\title{
THE APPLICATION OF THE THIERSCH GRAFT TO SPECIAL
} AREAS.

\author{
By T. POMFRET KILNER, F.R.C.S.,
}

Plastic Surgeon, St. Andrew's Hospital, Dollis Hill; London County Council; Queen Mary's Hospital, Roehampton; Princess Elizabeth of York Hospital for Children, Shadwell; and Lord Mayor Treloar Hospital, Alton.

My last article (Post-Graduate Journal, May, I934) confined itself to the preparation of the Thiersch graft and its application to surface areas: the present article will deal with its application to special regions. It has appeared to me wise, however, to make first some mention of the various forms of apparatus which have been devised to aid the skin-graft cutter of limited experience, for it has been pointed out by colleagues that, although the simple wood slip and knife method may be easy to the man who is continually cutting grafts, it does not prove so easy to the occasional skin grafter. I maintain, however, that the simpler the apparatus for this particular work the more rapidly is the technique mastered, and I myself seldom have recourse to any of the instruments I am about to mention.

\section{Mechanical Aids to Graft Cutting.}

The essential point common to all is some means of providing a flat skin surface from which the graft may be cut. In I92I, in association with my then colleague, T. Jackson ${ }^{(1)}$, I described a simple skin-stretching device illustrated in use in Fig. I. This, when made with sufficiently fine and sharp points on its

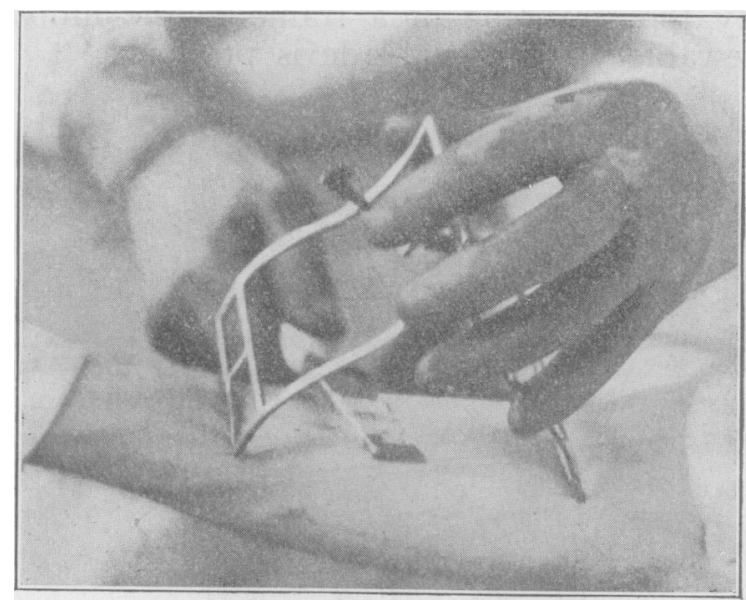

FIG. I. Skin Stretcher in use on Arm.

cross-bars, does materially help in graft cutting. It locks automatically and avoids that "bellying" of the underlying tissues which is often so troublesome.

V. P. Blair employs a metal box attached to a suction apparatus, and this, when suitably lubricated and drawn along the surface, draws up the skin in a flat line in front of the knife. Neither of these devices provides automatic knife action, and practice with the knife and patience are still required. 
The late Mr. R. Lane Joynt, F.R.C.S., of Dublin, an expert craftsman in metals, designed an instrument which provides both flat surface and automatic cutting (Fig. 2).

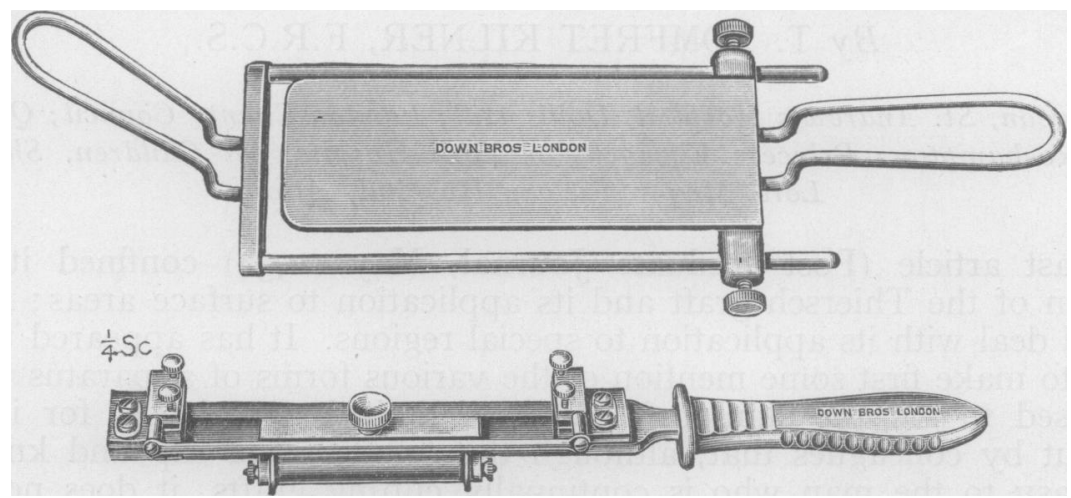

FIG. 2. Lane Joynt's skin-graft cutting apparatus. The thickness of the graft can be varied by adjustment of the knife.

The principle is that employed in leather splitting, the knife edge following a roller and being adjustable for wide variation in thickness of graft. This instrument works perfectly so long as the knife is kept sharp and the moving parts are given reasonable care and attention. My sole objections to it are that its cost is high and that the need for insertion of subcutaneous plates makes of graft-cutting a major instead of a minor operation.

I have recently seen and handled a new apparatus designed by Mr. G. Humby, working on somewhat similar lines but in which the need for subcutaneous plates is avoided by the strapping of a frame to the limb (Fig. 3). In this a removable and renewable wafer-steel blade is provided.

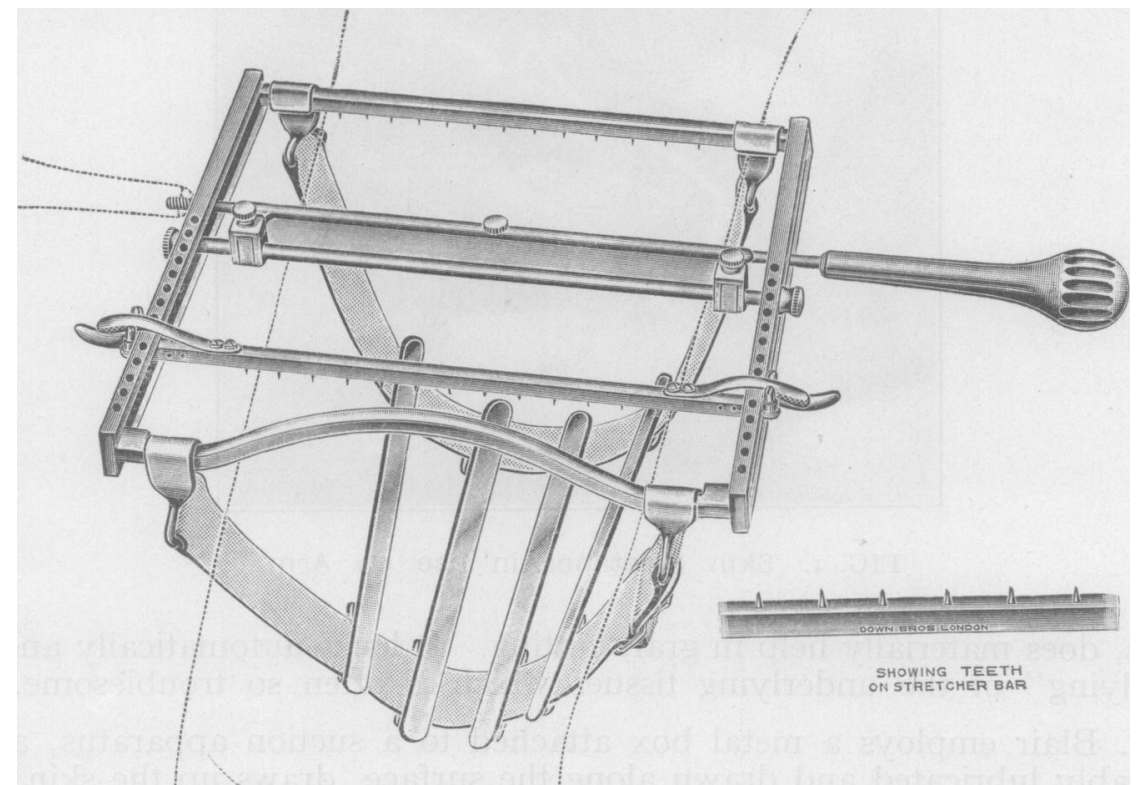

FIG. 3. Humby's skin-graft cutting apparatus. This, also, can, be adjusted to cut grafts of different thickness. 
Any instrument which will provide a ready and certain means of graft-cutting must prove a boon to surgeons and patients alike, but as few surgeons have time and patience to adjust and care for mechanical devices I find myself still the advocate of the simpler method previously described.

Thiersch graft skin is particularly suitable for replacing lost mucous membrane, for mucous membrane itself is difficult to procure in anything like quantity and is, for the most part, placed in rather inaccessible positions. The use of epidermal grafts for this purpose in the eyesocket and in the mouth will be taken as examples, and its use on the eyelid will also be described.

\section{Orbital Graft.}

The distorted eye socket is prepared by careful excision of all mucous membrane from the inner aspect of the eyelids and from the back wall of the socket. It is better to make a completely skin-lined cavity than leave mucous membrane remnants producing discharge and spoiling the appearance of an artificial eye. For the removal to be done efficiently, suction apparatus is almost imperative, for bleeding is usually troublesome and no other means will keep the mucosal surfaces clearly under observation while they are being separated and cut away with scissors. Both upper and lower fornices are deepened, to an extent beyond the normal, by incision and by the removal of any scar tissue encountered in these regions. Hæmostasis is obtained by picking up and twisting any bleeding vessels, and by means of ice cold compresses.

Care should be taken in using the suction apparatus lest undue traction is made on orbital fat, for it is desirable that this should be disturbed as little as possible and that a smooth surface should be left to receive the graft.

A Stent mould is made of the over-large cavity thus produced, the eyelids being drawn gently together over it either by traction sutures or fine tissue hooks during the setting process which is hastened by a trickle of iced saline from a dental chip syringe. Careful attention should be given to filling out the fornices, and the Stent should be moulded into disc-shaped form.

Instead of the Stent mould I frequently employ in this situation hollow glass shapes made for me by Dr. Millauro.

Although it is not altogether essential, but because disappointments have resulted from the too early extrusion of the mould in the after-treatment of these cases, the edges of the eyelids are usually freshened in their middle thirds at this stage in readiness for approximation by suture later.

It is a wise precaution to mark the mould in some convenient manner (as by scratching with a needle) to indicate its front surface and one or other of its extremities, for these moulds are almost symmetrical in shape, and these points are not always easy to recall when the mould has been removed and the graft applied.

When set, the mould is removed and dried and is then draped with the Thiersch graft, raw surface outwards, the junction line of graft edges being arranged to lie in front in line with the palpebral fissure. 
If the graft is really an epidermal one and is amply large for the job, no difficulty will be experienced in spreading it over the mould. If it is thick and more nearly approaching the Wolfe graft in character (and, therefore, unsuitable for use in this region because it will almost certainly grow hairs) its edges will continually curl back and give endless trouble in spreading.

The graft-covered mould is inserted and the freshened portions of the eyelid margins are approximated by a running subcuticular suture. A mild pressure dressing of gauze or wool is applied over a piece of Tulle Gras and is retained in position by a crêpe bandage.

Unless pain or tenderness to pressure over the dressing is experienced, the area is left undisturbed for a week when any discharge is gently mopped away and the eyelid suture is removed.

Gentle irrigation or mopping of the open parts of the palpebral fissure is carried out daily, and the region is kept covered by pad and bandage or eye shade.

The longer the mould can be retained, the more certain is it that a perfectly epithelialized cavity will be found when it is removed. It is for this reason that I frequently employ a glass shape in preference to a Stent mould, for the surface of the latter is liable to become macerated after a time and appears to produce a certain degree of irritation.

The patient leaves Hospital soon after the first dressing and continues to carry out the simple post-operative toilet himself, returning periodically for inspection. Occasionally inflammatory reaction is encountered, due to retention of discharge behind the mould, or to neglect to keep the open parts of the palpebral fissure draining freely. This complication is not serious and is readily dealt with by free irrigation.

In four to six weeks, when all danger of contraction in the grafted area is past (and this region above all others is especially prone to contraction), the bond of union between the eyelids is divided by a single cut with fine scissors. No anæsthetic, or at most the injection of a few drops of local anæsthetic solution, is required for this. The mould is removed and the socket is mopped clear of the epithelial debris arising from original excess of graft, or from desquammated surface layers.

At this stage a normal shaped artificial eye of larger-than-normal size is fitted. If such a prosthesis is not immediately available, the mould is replaced and the patient carries out a daily toilet of the socket until he can attend the artificial eye maker. Eyes of gradually decreasing size are fitted and finally one of correct shape, size and colour is prepared.

It seldom happens that a socket is made too large: very frequently insufficient allowance is made for subsequent contraction.

Fig. 4, illustrates a case treated in the manner described.

A reference (2) is given at the end of this article to a modification of this method applicable to the treatment of symblepharon. 


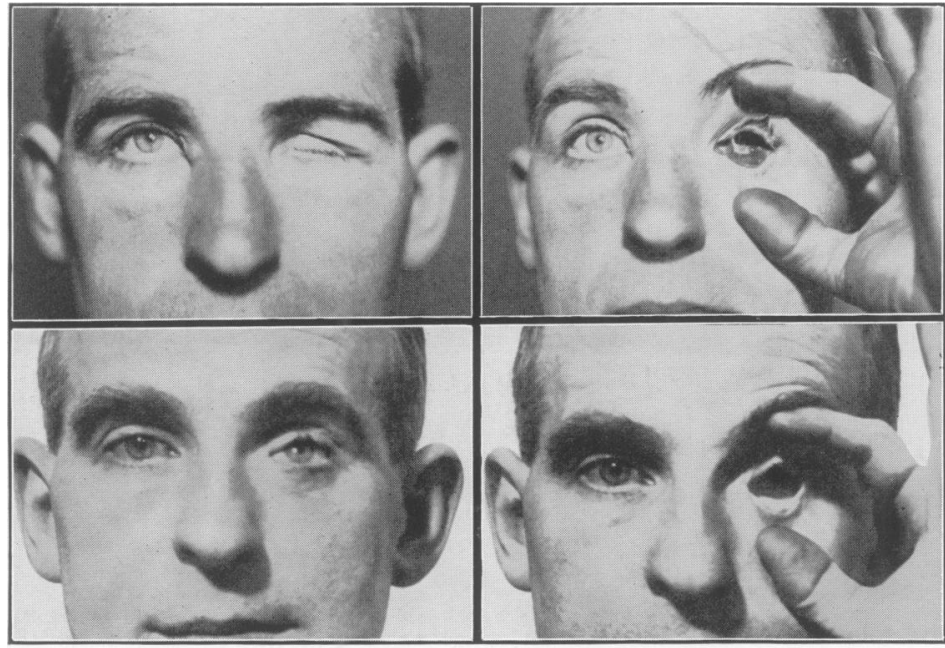

FIG. 4

Distorted eye-socket, incapable of carrying an artificial eye, treated by Thiersch grafting on a mould.

Large skin-lined pocket readily accommodates a full-sized artificial eye made by Dr. Millauro.

FIG. 4

FIG. 6

Extensive nitric acid burn of face.

Severe Ectropion of eyelids and eversion of upper lip treated by Thiersch grafting.

In this case other forms of graft were required elsewhere; the eyebrows were restored by free fullthickness hair-bearing grafts while the deformity of the lower lip and chin was corrected by means of a tubed-pedicle flap from the abdominal wall transferred via an attachment to the wrist.

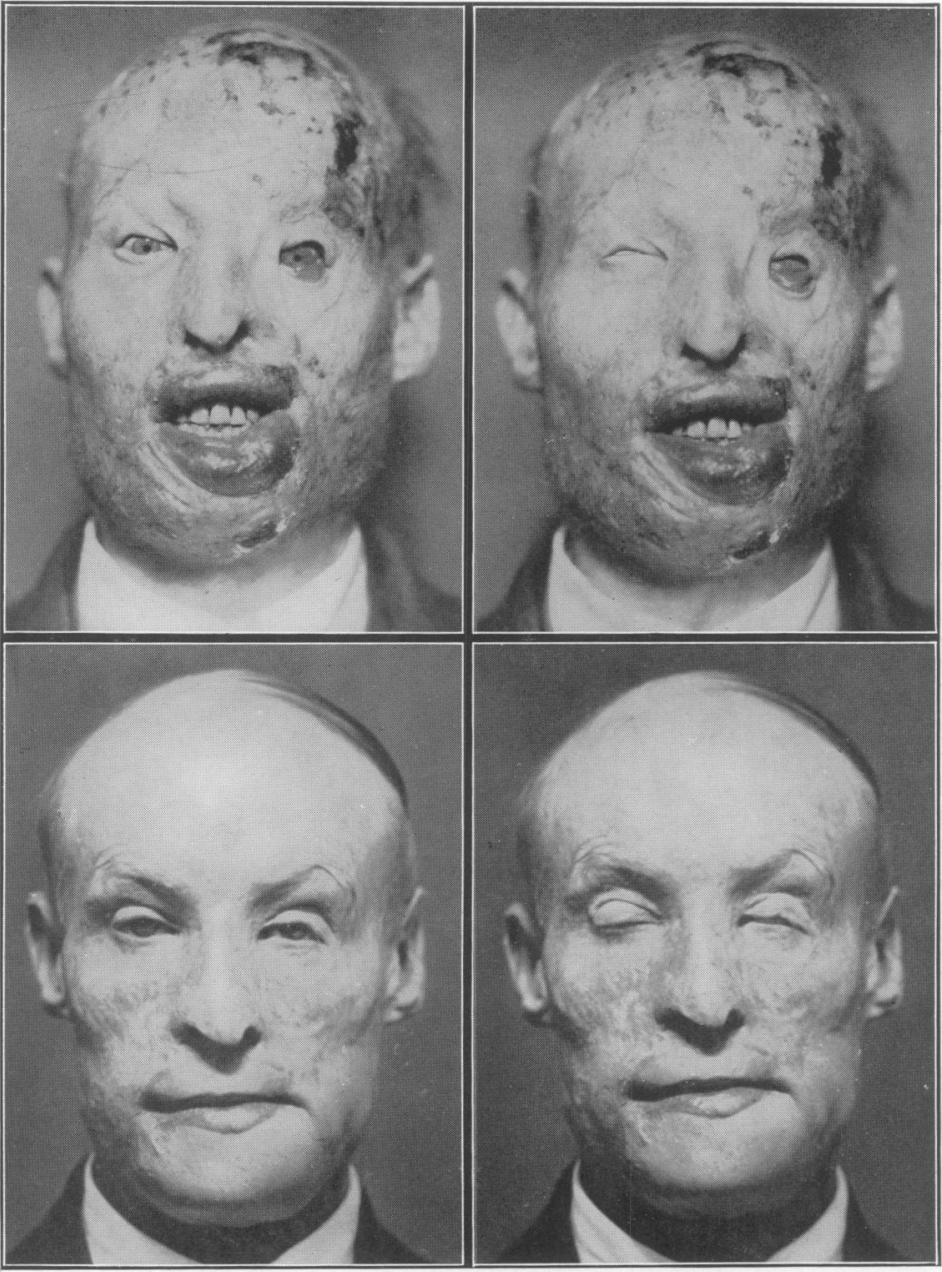


FIG. 8

Extreme retrognathism camouflaged by freeing the soft tissues from the underdeveloped mandible. Thiersch grafting the large pocket thus produced and filling this later by a vulcanite prosthesis.

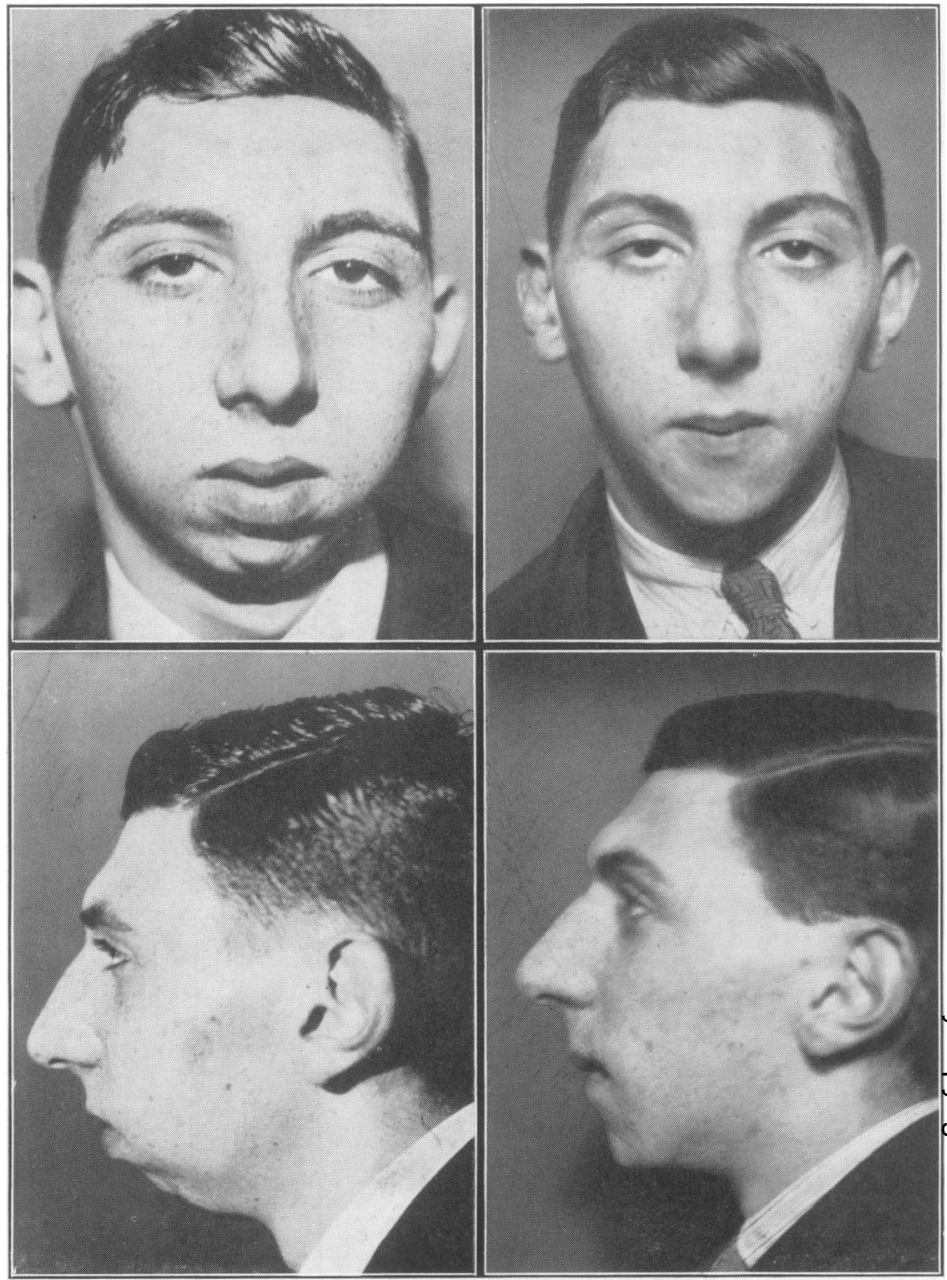

FIG. 8

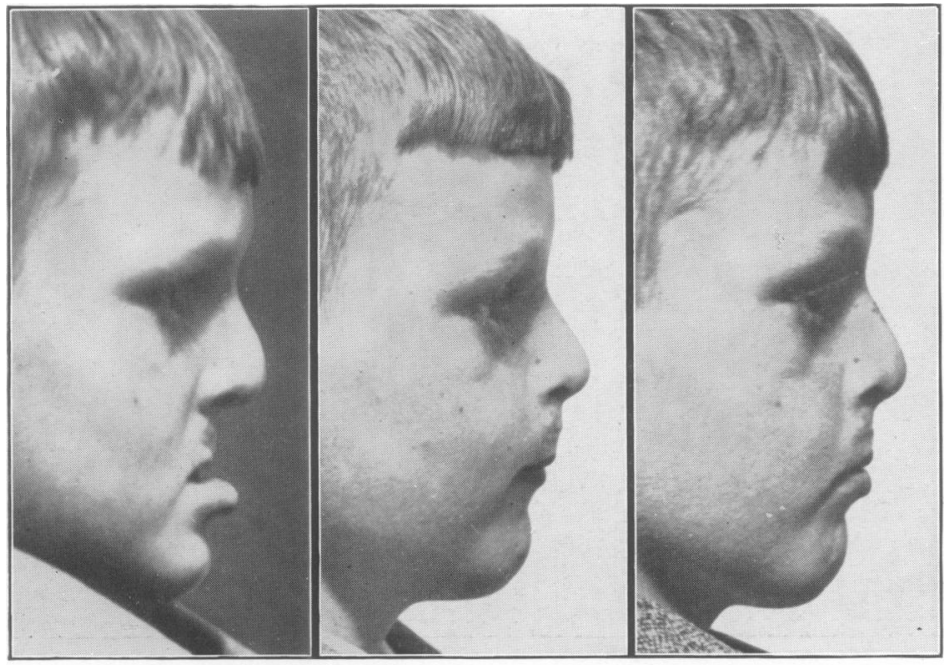

FIG. 9

The tight retroposed upper lip, so frequently resulting from the repair of a bilateral cleft lip, freed and brought forward by Thiersch graft and prosthesis.

Splint for skin-graft and final denture were made by Mr. S. J. F. Webb. 


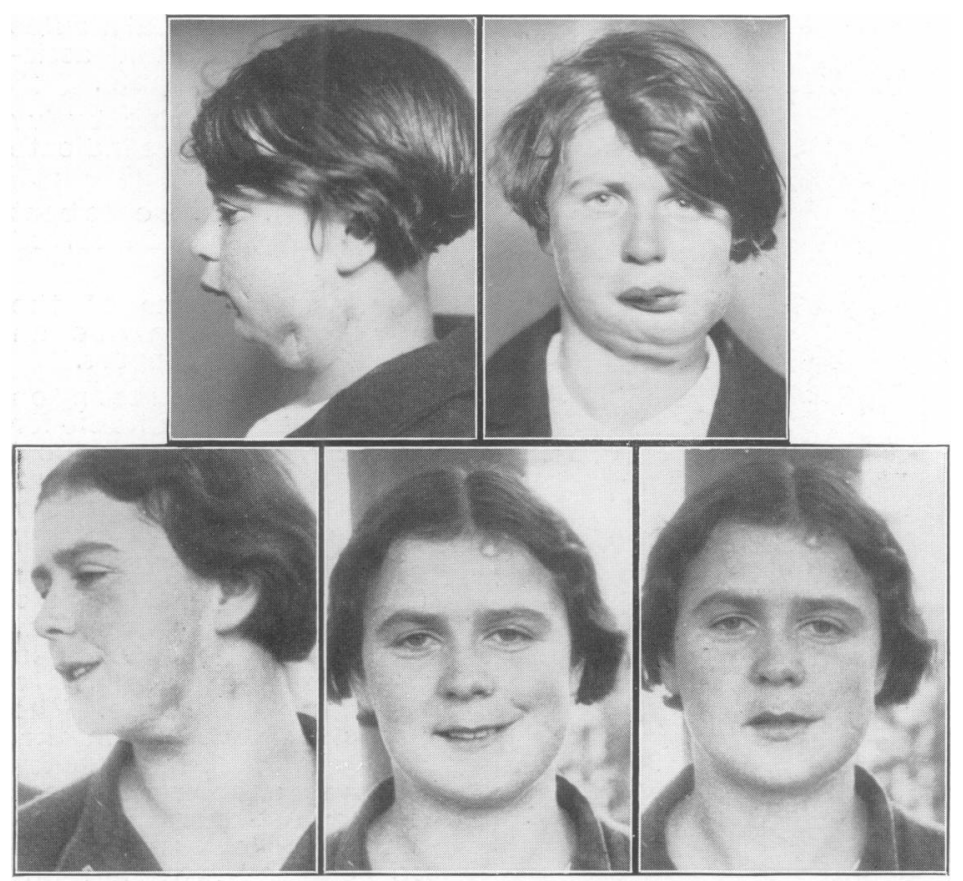

FIG. 7

Old Osteomyelitis of the left side of the mandible with loss of bone and non-union.

The mandible was repaired by a bone-graft from the ilium. Following this the buccal sulcus was reconstructed by means of a Thiersch graft applied on a mould. This made possible the fitting of a denture which restored masticatory function and, at the same time, built out the contour of the left side of the face.

Splints for bone graft and skin graft and final denture were made by $\mathrm{Mr}$. A. L. Fraser.

FIG. 7

FIG. 10

Luetic destruction of all nasal support and hard palate.

Nose freed from bone via upper buccal sulcus incision: destroyed mucosal lining made good by Thiersch graft on a mould replaced later by vulcanite prosthesis.

Final contour given by hinged cartilage graft and nasal portion of prosthesis discarded.

Prosthetic work by Mr. F. Hemsted.

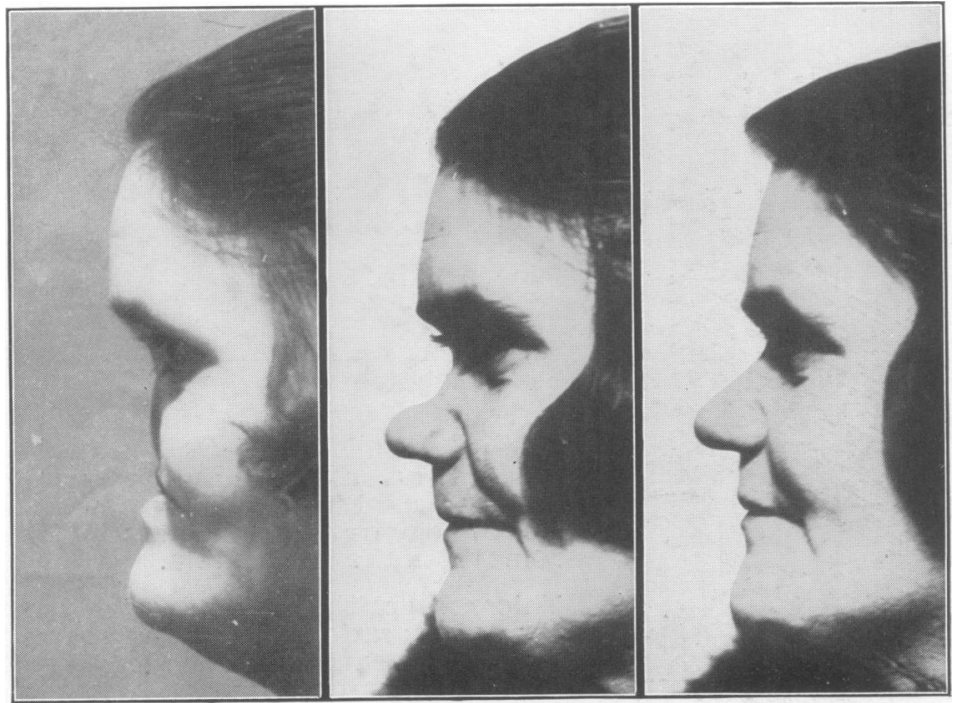

FIG. $\quad 10$ 


\section{THE THIERSCH GRAFT. ITS PREPARATIONS AND USES.}

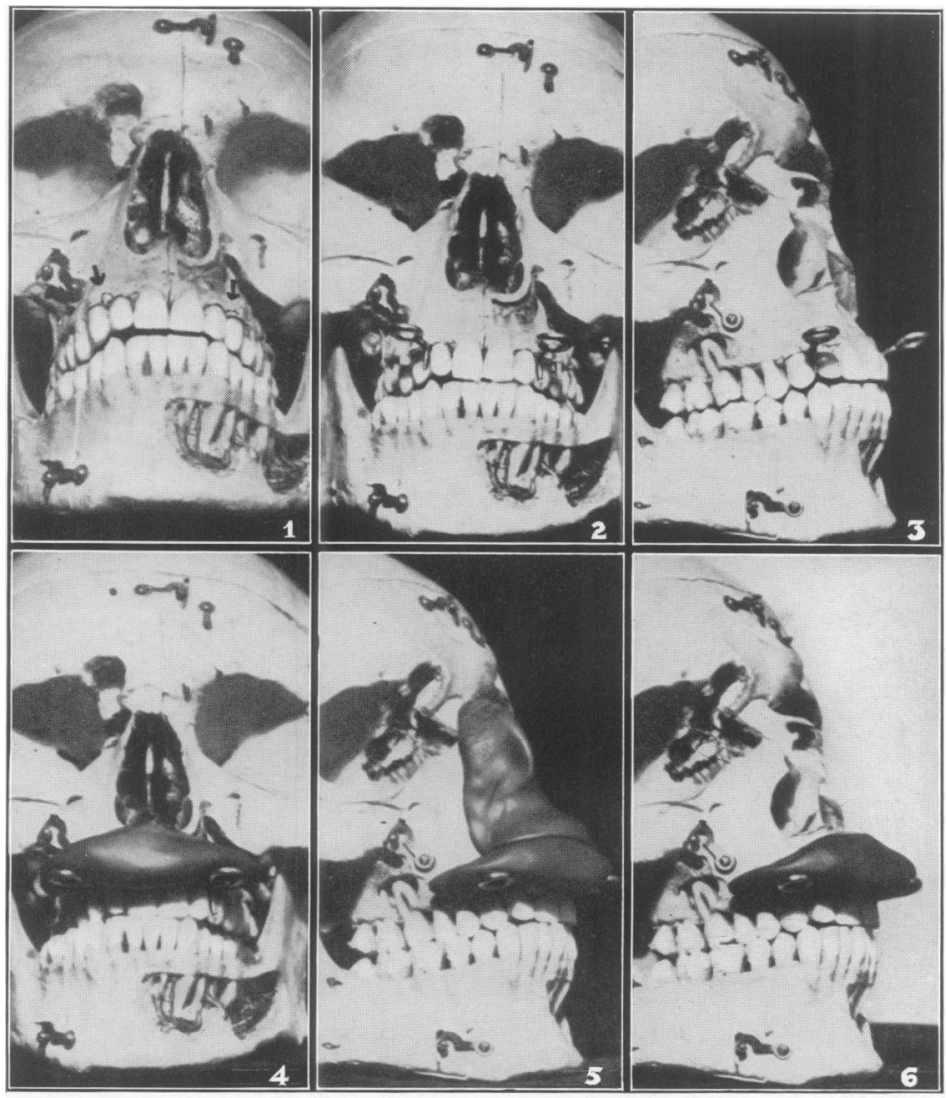

FIG. 11

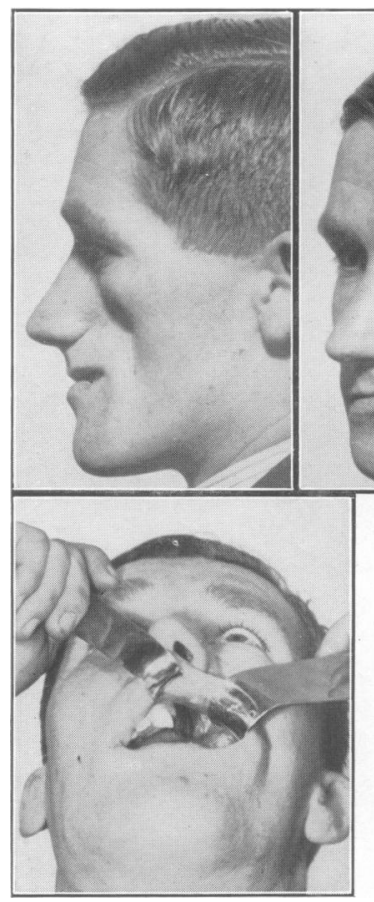

This photographic record is included to illustrate the severe, yet avoidable, deformity produced by removal of the left maxilla.

Thiersch grafting on a mould at the time of operation would have maintained a normal contour and given perfect intra-oral healing without subsequent contraction.
FIG. 11

Method advocated for the support of intra-oral moulds when expert dental assistance is not available.

(1). E yelet wiring by Ivy technique. Arrows indicate wire loops.

(2) and (3). Screw eyes bent at right angles and inserted in eyelets.

The ring portions of the screw eyes provide an excellent shelf support.

(4) and (6). Mould resting on screw eyes and suitable for deepening the upper buccal sulcus and bringing forward the lip in the secondary correction of cleft lip deformity.

(5). A large nasal mould superimposed on that shown in (4) as used in the treatment of I uetic deformity of the nose. The use of two moulds in this manner allows of easy removal and replacement during post-operative treatment. The lower mould can be removed with a minimum of elevation and this leaves ample room for manipulation of the upper and larger mould.

At the time of first removal the upper mould is drilled opposite the nares in order to restore nasal breathing. 


\section{Ectropion.}

Whilst dealing with the orbital region a brief description may be given of the treatment of cicatricial ectropion. The details of the technique employed are well illustrated in Fig. 5. The principle involved is that already stressed as essential in all free skin-grafting, namely, accurate pressure dressing giving complete

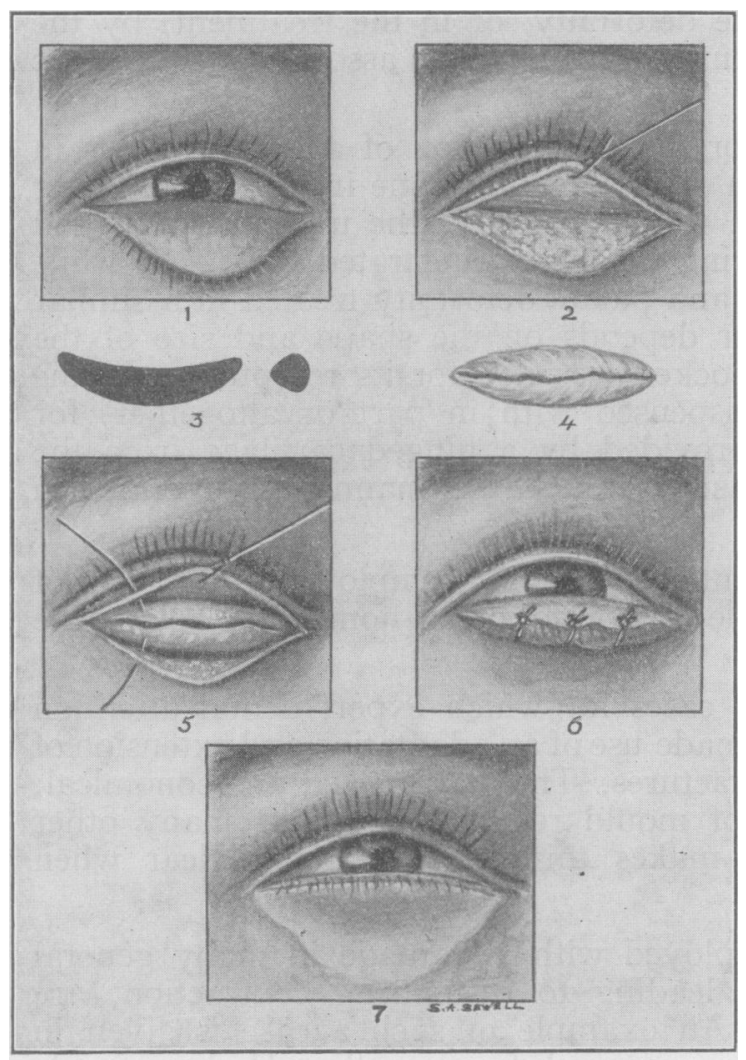

Fig. 5. Diagrams illustrating the technique employed in the treatment of Ectropion.

(1) Incision immediately outside eyelashes from canthus to canthus.

(2) All scar bands divided and eyelid brought into overcorrected position.

(3) Stent mould.

(4) Mould draped with skingraft.

(5) Graft and mould in position. Commencement of fixation suturing.

(6) Sutures in position: eyelid everted over mould.

(7) Result of grafting.

FIG. 5 .

apposition between graft and bed. In the eyelid region this desideratum is obtained by stretching the eyelid outwards over the graft-covered mould by sutures. I am convinced that this, the original method of applying the graft developed by Gillies at the Sidcup Hospital, is superior to any other, for only by this means can efficient over-correction be obtained, and so allowance made for some degree of subsequent contraction.

For a time the newly grafted surface remains depressed, but this hollowness quickly disappears on light grease massage. Fig. 6 illustrates a case treated by this method.

Early grafting of ectropic eyelids in burn cases is to be most strongly advocated if corneal ulceration and opacity are to be avoided. Further contraction may occur in such cases and ectropion may re-appear, but the operation is simple and can readily be repeated. 


\section{Intrabuccal Grafting.}

In the mouth the Thiersch graft is chiefly useful for the reconstruction of an obliterated sulcus. In post-war surgery such deformity was extremely common after gun-shot fractures of the mandible or maxilla. Fig. 7 illustrates a parallel case treated recently. In civil practice the "buccal inlay", as it has been termed, finds its chief fields of application in restoring contour in the chin region, in the premaxillary region in cleft lip and palate deformity, or in the treatment, by the Gillies method, of the "dish-faced" deformity so frequently associated with luetic infection.

It is likely to be used increasingly for the re-formation of a buccal sulcus in edentulous cases with excessive absorption of the alveolar bone in which the fitting of stable dentures is otherwise impossible. An example of the use of this method in a case of extreme retrognathism following trismus is illustrated in Fig. 8, while Fig. 9 illustrates a case of severe cleft lip and palate deformity treated in a similar manner. In these cases the final contour depends on the shape and size of the dental prosthesis fitted in the skin-lined pocket provided for its reception. In the luetic nose the original mould is later dispensed with in part or altogether, for the final support of the nose bridge is provided by a hinged cartilage from the patient's 7 th or 8th costal cartilage. A case treated in this manner is illustrated in Fig. Io.

For work of this kind in the mouth dental apparatus is employed in the form of a metal-cap splint carrying an adjustable flange to press home and retain the Stent mould.

In recent years, frequently faced by cases for which expert dental attention could not be obtained or afforded, I have made use of an adaptation and extension of the Ivy method of eyelet-wiring for jaw fractures. This has proved an economical, and in every way satisfactory, method of mould retention and has many other applications. The illustration, Fig. II, makes this method amply clear when considered with its full legend.

Intrabuccal skin grafting can be employed with advantage in many general surgical conditions where raw surfaces, leading to disfiguring contraction, are commonly left to close by granulation. An example of such a case is given in Fig. I2, where the left maxilla has been removed for growth. Had a simple half denture been prepared beforehand in this case, provided with clip fixation to the teeth on the right side, and with a projection to the left to support a Stent mould, the whole of the raw surface left by removal of the maxilla could have been readily epithelialized and all disfigurement prevented. Modification of the denture later would have built out the cheek in perfect form, and the necessity for the further operation now required would have been avoided.

In the absence of dental apparatus or when teeth are not available for the alternative method of fixation described above, moulds may be held in place, long enough to ensure satisfactory grafting, by suitably placed silkworm gut sutures.

To finish on the same note as that sounded at the beginning of these two articles, there is little or no excuse in surgery for the leaving of any raw surface for painful dressing, infection, and ultimate healing by contracted scar.

RETERENCES :

(1) Skin Grafting in the Buccal Cavity. Kilner. T. P. and Jackson, T. British Journal of Surgery, Vol. IX., No. 33, 1921.

(2) Symblepharon: Its treatment by Thiersch and Mucous Membrane Grafting. Gillies, H. D. and Kilner. T. P. Trans. Ophth. Boc. XITV. 1920. 